\title{
Structural, Morphological and Optical Study of Bismuth and Zinc Co-Doped Yttrium Oxide Prepared by Solvothermal and Wet Chemical Method
}

\author{
G. Bhavani ${ }^{a, *}$ AND S. GANESAN ${ }^{b}$
}

${ }^{a}$ Department of Physics, Jansons Institute of Technology, Coimbatore, Tamilnadu, India

${ }^{b}$ Sri Shakthi Institute of Engineering and Technology, Coimbatore, Tamilnadu, India

(Received February 17, 2015; revised version October 10, 2016; in final form November 1, 2016)

Yttrium oxide $\left(\mathrm{Y}_{2} \mathrm{O}_{3}\right)$ is the most familiar yttrium compound, which is popularly known as host for ion doping of other rare earth elements. Bismuth ion $\left(\mathrm{Bi}^{3+}\right)$ is well known as an activator and sensitizer in several particular phosphors. Zinc oxide $(\mathrm{ZnO})$ nanomaterial, having a wide band gap, is one of the promising candidates for general illumination applications due to its high optical transparency and color tenability bismuth (Bi) and zinc ( $\mathrm{Zn}$ ) co-doped $\mathrm{Y}_{2} \mathrm{O}_{3}$ samples are synthesized by simple precipitation techniques like solvothermal and wet chemical methods. The prepared samples were characterized using X-ray diffraction, scanning electron microscope, energy dispersive X-ray spectra, ultraviolet-visible absorbance spectroscopy and photoluminescence spectrophotometry. Ultraviolet-visible absorption studies showed absorption only around $340 \mathrm{~nm}$ whereas photoluminescence shows peaks around $500 \mathrm{~nm}, 680 \mathrm{~nm}$, and $1020 \mathrm{~nm}$ for $\mathrm{Bi}$ and $\mathrm{Zn}$ co-doped $\mathrm{Y}_{2} \mathrm{O}_{3}$. The photoluminescence spectrum shows emission in blue region $(500 \mathrm{~nm})$ due to $\mathrm{Zn}$ dopant and red and near infrared region (680 and $1020 \mathrm{~nm})$ due to Bi dopant. This is a new material which can effectively work as an efficient and cheap red phosphor.

DOI: $10.12693 /$ APhysPolA.130.1373

PACS/topics: 78.55.-m, 61.05.C-, 61.72.sd

\section{Introduction}

Yttrium is one of the most important rare-earth element. Yttrium compounds show promise for applications such as high quality phosphors, catalysts, up-conversion materials and fine ceramics because of their optical and catalytic properties and high-temperature stability. Yttrium oxide $\left(\mathrm{Y}_{2} \mathrm{O}_{3}\right)$ is the most familiar yttrium compound, which is popularly known as host for ion doping of other rare earth elements. Luminophores based on $\mathrm{Y}_{2} \mathrm{O}_{3}$ are promising materials for electronics and scintillation and laser technology $[1,2]$. Such luminophores activated by ions of rare-earth elements are especially common. Moreover, $\mathrm{Y}_{2} \mathrm{O}_{3}$ activated by another group of important activators, like zinc and the so-called mercury-like ions, of which bismuth ion $\left(\mathrm{Bi}^{3+}\right)$ is one, are poorly studied $[2,3]$. Such compounds can be used as scintillators in luminescent screens or mercury-free luminescent photomultiplier bulbs. The spectral properties of these materials have been well studied [4-6]. Therefore, the investigation of $\mathrm{Y}_{2} \mathrm{O}_{3}$ is timely and addressed herein. An attempt has been made to enhance the properties of $\mathrm{Y}_{2} \mathrm{O}_{3}$, the host lattice by adding two dopants, $\mathrm{Bi}$ and $\mathrm{Zn}$.

Methods for improving the efficiency of materials have centred on improving the physical properties of materials by controlling surface morphology and size of materials and reducing concentration quenching, etc. These properties can be controlled by preparation technique and processing temperatures. The method of co-precipitation

\footnotetext{
* corresponding author; e-mail: bhavaneeg@gmail.com
}

is the most promising for making the initial raw materials since it makes it possible to synthesize nanosize powders which are homogeneous with respect to the particle size and chemical composition. This method ensures a high degree of completion of the reaction. The advantages of the method are the comparative simplicity and absence of complicated process operations and power-consuming equipment. Using it in large-scale production will significantly reduce the cost of the final products. Hence the co-precipitation methods like solvothermal and wet chemical methods are used for the synthesis of $\mathrm{Y}_{2} \mathrm{O}_{3}$ in the present work.

In this paper $\mathrm{Y}_{2} \mathrm{O}_{3}: \mathrm{Bi}, \mathrm{Zn}$ powders were prepared for the first time by simple methods as solvothermal and wet chemical methods where the structural, morphological, elemental and optical properties were studied using X-ray diffraction (XRD) and scanning electron microscopy (SEM), ultraviolet-visible absorbance spectroscopy (UV-vis) and photoluminescence (PL) spectrophotometry, respectively. Elemental analysis was studied using energy dispersive X-ray spectra (EDX).

\section{Experimental}

\subsection{Solvothermal method}

In this method, $\mathrm{Bi}$ and $\mathrm{Zn}$ co-doped $\mathrm{Y}_{2} \mathrm{O}_{3}$ samples BBZ1, BBZ2, and BBZ3 were prepared by dissolving $0.6 \mathrm{~g}$ of yttrium nitrate hexahydrate $\left(\mathrm{Y}\left(\mathrm{NO}_{3}\right)_{3} \cdot 6 \mathrm{H}_{2} \mathrm{O}\right)$ in $160 \mathrm{ml}$ of absolute ethanol under stirring. When $\mathrm{Y}\left(\mathrm{NO}_{3}\right)_{3} \cdot 6 \mathrm{H}_{2} \mathrm{O}$ was dissolved completely, $6.4 \mathrm{~g}$ of sodium hydroxide solid was dropped into those solutions. To prepare BBZ1, BBZ2, and BBZ3, $0.0015 \mathrm{~g}(0.00075 \mathrm{~g}$ of bismuth nitrate and $0.00075 \mathrm{~g}$ of zinc acetate dihydrate), 
$0.003 \mathrm{~g}(0.0015 \mathrm{~g}$ of bismuth nitrate and $0.0015 \mathrm{~g}$ of zinc acetate dihydrate), $0.006 \mathrm{~g}$ (0.003 g of bismuth nitrate and $0.003 \mathrm{~g}$ of zinc acetate dihydrate) were added to the resulting solutions. Then forfurther $30 \mathrm{~min}$ vigorous stirring was continued. After that the samples were heated at $433 \mathrm{~K}$ for $3 \mathrm{~h}$ in an oven and cooled to room temperature. The white powder formed at the bottom was washed with ethanol and distilled water several times to remove any possible remnants. Finally the product was dried at $353 \mathrm{~K}$ in an oven for $2 \mathrm{~h}$ [7]. Pure sample B Pure is prepared by following the same procedure but without the addition of dopant precursor.

\subsection{Wet chemical method}

In this method, the preparation of yttrium-bismuth precursor was achieved [8-11] involving a precipitation reaction between the yttrium nitrate, zinc acetate and bismuth nitrate and oxalic acid as precipitant agent. Precipitation was conducted at $353 \mathrm{~K}$ in an oven. Yttrium nitrate solution $(0.6 \mathrm{~g})$ was added together with oxalic acid $(0.9 \mathrm{~g})$ into diluted solution of oxalic acid (1:10) to prepare pure sample, C Pure. The precursor post precipitation stage consists of washing and drying. To prepare bismuth and zinc codoped yttrium oxide samples CBZ1, CBZ2 and CBZ3, $0.0015 \mathrm{~g}$ (0.00075 g of bismuth nitrate and $0.00075 \mathrm{~g}$ of zinc acetate dihydrate), $0.003 \mathrm{~g}$ $(0.0015 \mathrm{~g}$ of bismuth nitrate and $0.0015 \mathrm{~g}$ of zinc acetate dihydrate), $0.006 \mathrm{~g}$ (0.003 $\mathrm{g}$ of bismuth nitrate and $0.003 \mathrm{~g}$ of zinc acetate dihydrate) of dopant precursors were added to the resulting solutions. The precursor post precipitation stage consists in $24 \mathrm{~h}$ ageing, washing and drying [11].

\section{Characterization}

The powder XRD study was carried out using a Shimadzu XRD 6000 X-ray diffractometer using $\mathrm{Cu} K_{\alpha}$ radiation. The morphological investigation of the samples of $\mathrm{Bi}$ and $\mathrm{Zn}$ co-doped $\mathrm{Y}_{2} \mathrm{O}_{3}$ nanoparticles were performed in JEOL Model JSM - 6390LV Scanning Electron Microscope. Elemental analysis of the samples is done by EDAX JEOL Model JED-2300 make to determine the presence and percentage of bismuth, yttrium, zinc, and oxygen ions. UV-visible spectra for the samples were taken using JASCO UV-Vis-NIR spectrophotometer (Model V-570) in the wavelength range 200 to $1200 \mathrm{~nm}$. The photoluminescence spectrum was obtained by using FLUOROLOG, HORIBA YVON spectrophotometer.

\section{Results and discussion}

\subsection{XRD}

XRD pattern of pure and co-doped $\mathrm{Y}_{2} \mathrm{O}_{3}$ samples prepared by solvothermal and wet chemical method are shown in Figs. 1 and 2, respectively.

From Fig. 1, it was observed that the pure samples has broad hump and some emerging peaks with amorphous nature and the doped samples shows narrow peaks with

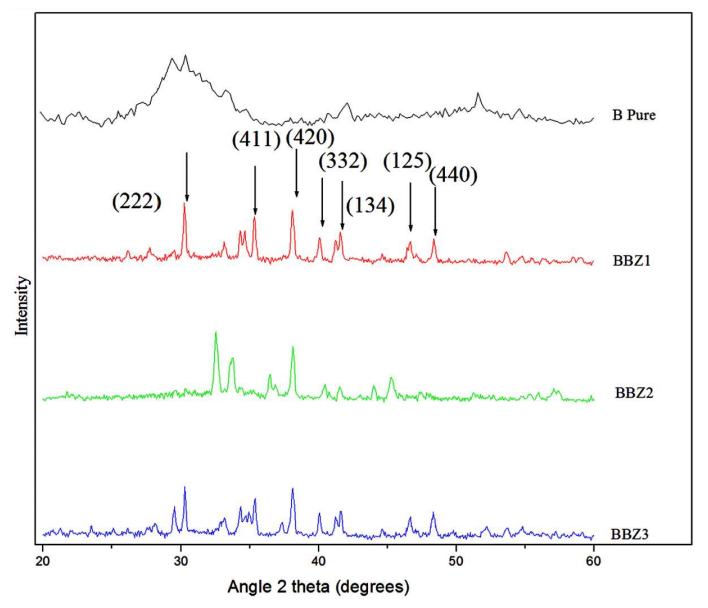

Fig. 1. XRD diffraction pattern of pure and $\mathrm{Bi}, \mathrm{Zn}$ codoped $\mathrm{Y}_{2} \mathrm{O}_{3}$ samples prepared by solvothermal method.

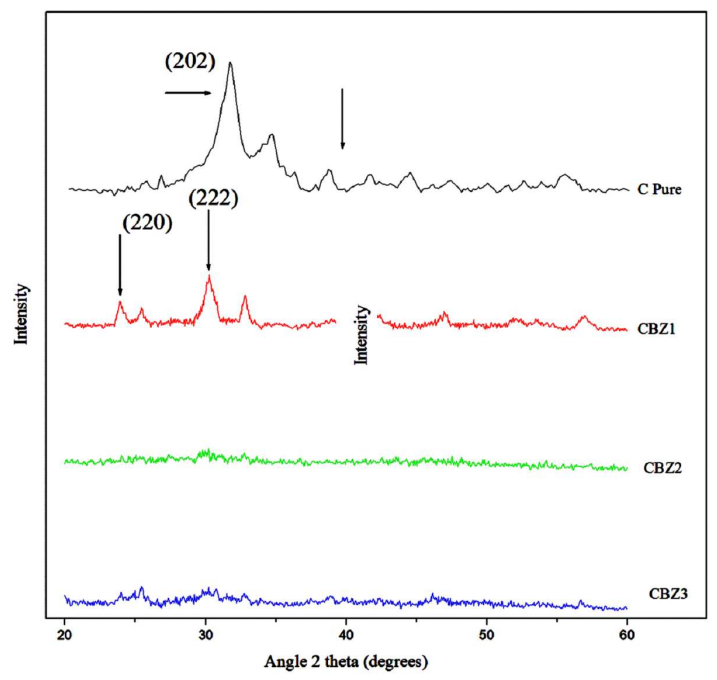

Fig. 2. As in Fig. 1 but for wet chemical method.

amorphous nature. Except for some peaks at $38^{\circ}$ and $48^{\circ}$ (due to the presence of cubic phase of $\mathrm{Y}_{2} \mathrm{O}_{3}-$ JCPDS 895591), most of the peaks of BBZ1 and BBZ3 samples show difference in relative intensity which may be due to the distortion in the structure due to the dopants. This effect is mainly due to the difference in ionic radii between the main element and the dopant ions. Initially crystallite size decreases with dopant concentration then it increases slightly [12]. However in case of BBZ2 samples additional peaks were observed around $33^{\circ}$ and $37^{\circ}$ (which may be due to the presence of cubic phase of $\mathrm{Y}_{2} \mathrm{O}_{3}$ - JCPDS 895591), $34^{\circ}$ (which may be due to the presence of zinc oxide - JCPDS 361451), $41^{\circ}$ and $45^{\circ}$ (which may be due to diffraction of tetragonal structured $\beta$ - $\mathrm{Bi}_{2} \mathrm{O}_{3}$ - JCPDS 290236), $42^{\circ}$ (which may be due to monoclinic phase of $\mathrm{Y}_{2} \mathrm{O}_{3}-$ JCPDS 440399). Hence $\mathrm{XRD}$ diffraction for the co-doped samples prepared by solvothermal method, with 0.25 and 1 wt\% of dopant concentration show peaks mainly due to cubic phase of $\mathrm{Y}_{2} \mathrm{O}_{3}$ whereas the co-doped sample with $0.5 \mathrm{wt} \%$ of 
dopant concentration show additional peaks along with cubic $\mathrm{Y}_{2} \mathrm{O}_{3}$, due to tetragonal phase of $\beta-\mathrm{Bi}_{2} \mathrm{O}_{3}$ and monoclinic phase of $\mathrm{Y}_{2} \mathrm{O}_{3}$ and zinc oxide. It proves that not all $\mathrm{Zn}$ and $\mathrm{Bi}$ are entered in $\mathrm{Y}_{2} \mathrm{O}_{3}$ lattice structure and there is a presence of mixed phases of both cubic and monoclinic $\mathrm{Y}_{2} \mathrm{O}_{3}$ or the development of mixed phases of both $\mathrm{ZnO}$ and $\beta-\mathrm{Bi}_{2} \mathrm{O}_{3}$.

From Fig. 2, it was observed that the pure samples have broad peaks characteristic of monoclinic primitive (JCPDS 391063) structure of yttrium oxide and the doped sample of lower concentration shows narrow peaks with some amorphous nature, too. The peaks at $24^{\circ}$ and $30^{\circ}$ (due to the presence of cubic phase of $\mathrm{Y}_{2} \mathrm{O}_{3}$ - JCPDS 895591), $25^{\circ}$ (occurs at both zinc oxide JCPDS 391451 - and $\left.\beta-\mathrm{Bi}_{2} \mathrm{O}_{3}-\mathrm{JCPDS} 290236\right)$ and $32^{\circ}$ (occurs at cubic $\mathrm{Y}_{2} \mathrm{O}_{3}-$ JCPDS 895591, $\mathrm{ZnO}$ JCPDS 391451, and $\beta-\mathrm{Bi}_{2} \mathrm{O}_{3}-$ JCPDS 290236). It also shows that traces mixed phases of $\mathrm{Y}_{2} \mathrm{O}_{3^{-}}$, $\mathrm{ZnO}$-, $\beta-\mathrm{Bi}_{2} \mathrm{O}_{3}$ is present in this sample. Other doped samples with $0.5 \mathrm{wt} \%$ and $1 \mathrm{wt} \%$ as doping concentration show amorphous nature due to the distortion produced in the lattice [13]. It also has been observed that crystallite size decreases with dopant concentration [12]. From the XRD studies of pure and $\mathrm{Bi}, \mathrm{Zn}$ codoped $\mathrm{Y}_{2} \mathrm{O}_{3}$, it was concluded that the co-doping with $\mathrm{Bi}$ and $\mathrm{Zn}$ increased the lattice parameters of the phosphor, due to the fact that the ionic radius of $\mathrm{Y}^{3+}(0.092 \mathrm{~nm})$ is slightly lower than that of $\mathrm{Bi}^{3+}(0.096 \mathrm{~nm})$ and higher than $\mathrm{Zn}^{2+}$ $(0.074 \mathrm{~nm})$. So $\mathrm{Bi}^{3+}$ and $\mathrm{Zn}^{2+}$ ions were expected to occupy the $\mathrm{Y}^{3+}$ sites in this phosphor. However it was not happening in case of BBZ2 and CBZ1 samples where the peaks were observed due to the presence of $\mathrm{ZnO}$ and $\beta-\mathrm{Bi}_{2} \mathrm{O}_{3}$.

It is also observed that the presence of two dopants distorts the lattice mostly and suppresses its crystalline nature and turns the sample into amorphous nature. The doped samples prepared by solvothermal method shows crystalline nature to some extent but with shift in peaks, due to the change in lattice parameters and it may be the preparation technique adopted which gives the slightly crystalline nature to the resultant sample. The addition of dopants was observed to suppress $\mathrm{Y}_{2} \mathrm{O}_{3}$ crystallization. This is similar to the case already discussed by Hao et al. [14]. Table I lists the details of composition and calculated crystallite sizes of pure yttrium oxide and bismuth doped yttrium oxide samples estimated from the well-defibed known Debye-Scherrer equation [15] (Fruth et al.)..

\section{2. $S E M$}

All the SEM images of the samples prepared by solvothermal method (B Pure, BBZ1, BBZ2, BBZ3), and wet chemical method (C Pure, CBZ1, CBZ2, CBZ3) are shown in Figs. 3 and 4. Pure yttrium oxide sample B Pure shows the cumulative nature of secondary particles which are made up of agglomeration of many primary particles. BBZ1 sample shows elongated crystals that are embedded in agglomerated flower-like crystal, whereas
TABLE I

Composition and XRD calculated crystallite size of pure and $\mathrm{Bi}, \mathrm{Zn}$ co-doped $\mathrm{Y}_{2} \mathrm{O}_{3}$ samples.

\begin{tabular}{c|c|c}
\hline $\begin{array}{c}\text { Sample } \\
\text { name }\end{array}$ & Composition & $\begin{array}{c}\text { Crystallite } \\
\text { size }[\mathrm{nm}]\end{array}$ \\
\hline BBZ1 & $\mathrm{Y}_{2} \mathrm{O}_{3}: \mathrm{Zn}, \mathrm{Bi}(0.25 \mathrm{wt} \%$ of $\mathrm{Y}$ precursor $)$ & 25.22 \\
BBZ2 & $\mathrm{Y}_{2} \mathrm{O}_{3}: \mathrm{Zn}, \mathrm{Bi}(0.5 \mathrm{wt} \%$ of Y precursor) & 20.43 \\
BBZ3 & $\mathrm{Y}_{2} \mathrm{O}_{3}: \mathrm{Zn}, \mathrm{Bi}(1 \mathrm{wt} \%$ of Y precursor) & 23.26 \\
C Pure & $\mathrm{Y}_{2} \mathrm{O}_{3}$ & 14.62 \\
CBZ1 & $\mathrm{Y}_{2} \mathrm{O}_{3}: \mathrm{Zn}, \mathrm{Bi}(0.25$ wt\% of Y precursor) & 38.89
\end{tabular}

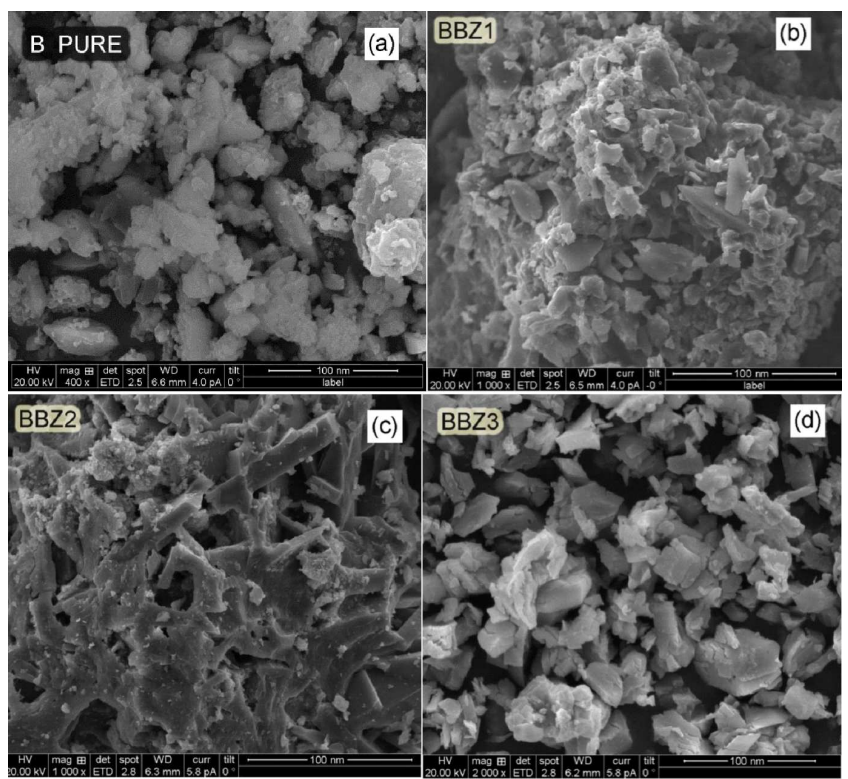

Fig. 3. SEM images of pure and $\mathrm{Bi}, \mathrm{Zn}$ co-doped $\mathrm{Y}_{2} \mathrm{O}_{3}$ samples prepared by solvothermal method.

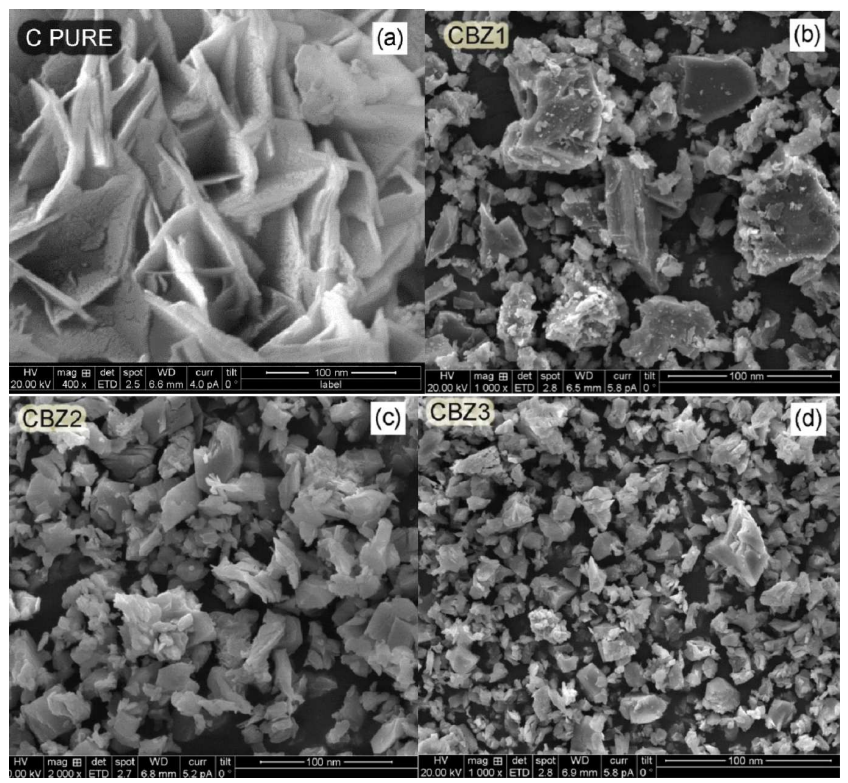

Fig. 4. As in Fig. 3 but for wet chemical method. 
BBZ2 sample shows more homogeneous shape where the crystals have a smooth plaquette-like shape that are stacked over each other and are separated by elongated crystals, and BBZ3 sample shows dispersed multishapes of crystals, flower like, polygonal, bars etc. Pure yttrium oxide sample $\mathrm{C}$ Pure shows flower like structure due to growth kinetics [16]. CBZ1 sample shows non-homogeneous dispersed particles whereas CBZ2 and CBZ3 show more homogeneous structure. The precipitating reagents could also influence the phosphor morphology and crystallite size as illustrated by the SEM images.

\section{3. $E D A X$}

From Fig. 5 of EDAX spectrum of Bi and Zn co-doped $\mathrm{Y}_{2} \mathrm{O}_{3}$ samples prepared by solvothermal and wet chemical method, the presence of the characteristic and distinct lines of $\mathrm{Y}(L), \mathrm{Bi}(L), \mathrm{Zn}(K)$ and $\mathrm{O}(K)$ have been identified. Though both the dopant precursor are taken in equal concentration, $\mathrm{Zn}$ percentage is found to be very less in the samples and it was found that Bi concentration is more and dominant in the sample compared with $\mathrm{Zn}$. It has been observed that for the samples prepared by solvothermal method weight percentage of $\mathrm{Bi}$ varies between 2 and 6 and that of $\mathrm{Zn}$ varies between 0.8 and 1.4 and for wet chemical method the range for $\mathrm{Bi}$ is between 3 and 7 and for $\mathrm{Zn}$ it is between 0.3 and 0.5. The reason may be due to the fact that since $\mathrm{Bi}$ is incorporated as $\mathrm{Bi}_{2} \mathrm{O}_{3}$ and $\mathrm{Zn}$ as $\mathrm{ZnO}$, the concentration of $\mathrm{Bi}$ in the resulting material is about twice or three times higher than that of $\mathrm{Zn}$. This has important consequences on the overall structure and properties [17]. It can be seen that, in the samples, the real dopant concentration is higher than the calculated value, thus illustrating that the precipitation of dopant and yttrium is achieved with variable rates.
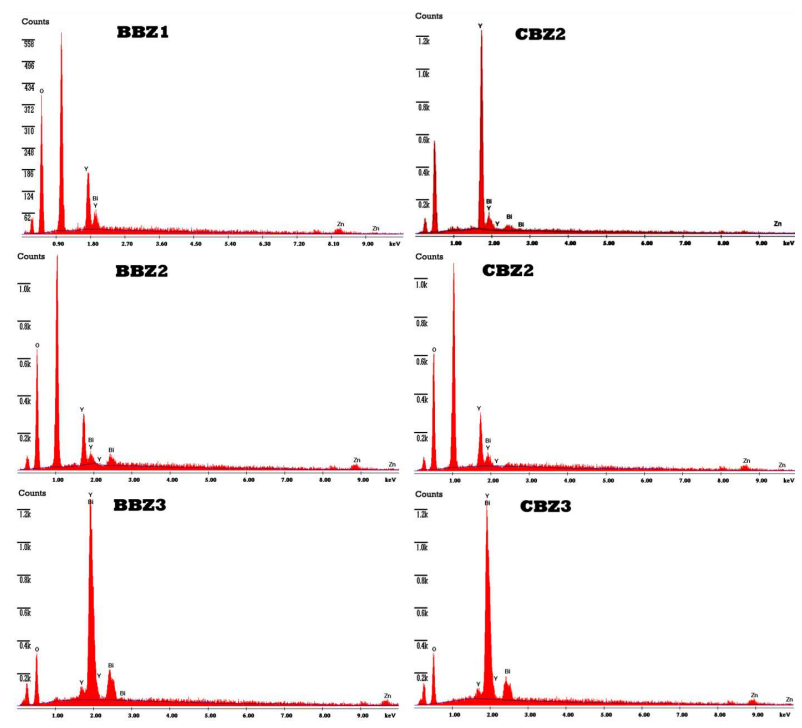

Fig. 5. EDAX spectrum of elemental analysis of the bismuth and zinc co-doped yttrium oxide samples prepared by solvothermal and wet chemical method.

\section{4. $U V$-vis absorption}

It has been observed from Fig. 6 of UV visible absorbance spectrum of pure and $\mathrm{Bi}, \mathrm{Zn}$ co-doped $\mathrm{Y}_{2} \mathrm{O}_{3}$ samples prepared by solvothermal method that pure sample shows absorption around $250 \mathrm{~nm}$ which is due to the absorption of $\mathrm{Y}_{2} \mathrm{O}_{3}$ [18]. Otherwise the absorption peak for the doped samples was shifted to around 325 and $350 \mathrm{~nm}$ for lower and higher concentration, respectively. An increase in the absorption intensity of the co-doped samples with increase of the dopant concentration is observed. This shift in the absorption between the doped and the undoped samples is due to quantum size effect, representing a change in band gap along with exciton features, resulting in a more discrete energy spectrum of the individual nanoparticles [19]. The effect of the quantum confinement on impurity depends upon the size of the host crystal [20]. As the size of the host crystal decreases, the degree of confinement and its effect increases [21].

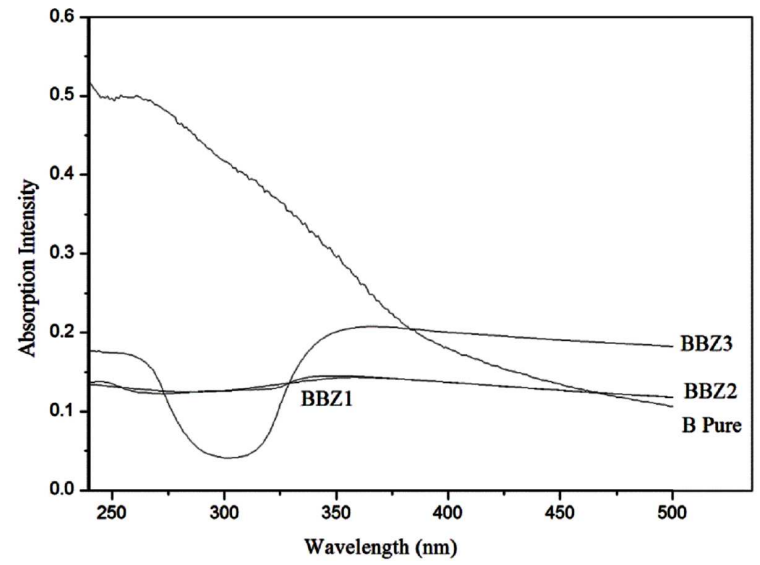

Fig. 6. UV visible absorption of pure and $\mathrm{Bi}, \mathrm{Zn}$ codoped $\mathrm{Y}_{2} \mathrm{O}_{3}$ samples prepared by solvothermal method.

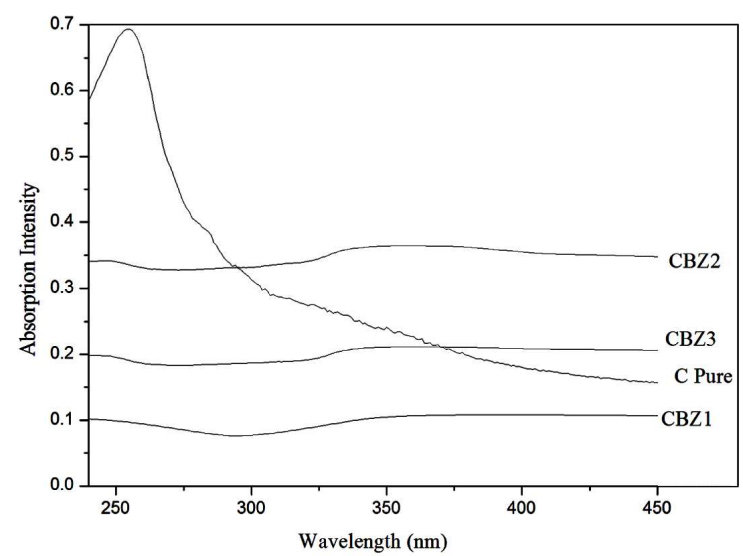

Fig. 7. As in Fig. 6 but for wet chemical method.

It has been observed from Fig. 7 of UV visible absorbance spectrum of pure and $\mathrm{Bi}, \mathrm{Zn}$ co-doped $\mathrm{Y}_{2} \mathrm{O}_{3}$ samples prepared by wet chemical method that pure sample shows absorption around $250 \mathrm{~nm}$ which is characteristic for $\mathrm{Y}_{2} \mathrm{O}_{3}$ as outlined before [18]. While in the doped 
samples it has been observed that the $\mathrm{Y}_{2} \mathrm{O}_{3}$ absorption band is shifted to around $325 \mathrm{~nm}$. Other than the peak around $325 \mathrm{~nm}$, the samples are found to be completely transparent over the visible region. With doping concentration, initially the absorption increases, then the absorption intensity decreases, this shows the distortion in the crystal structure with the increase in concentration of dopants of different ionic size. Band gap energy estimated for the samples based on UV visible absorption studies [22] is given in Table II. This result reveals that $\mathrm{Bi}, \mathrm{Zn}$ co-doped $\mathrm{Y}_{2} \mathrm{O}_{3}$ samples have a weak absorption for light in the wavelength range of 300-340 nm. Though the samples prepared by both the methods show weak absorption, the absorption intensity is high for samples prepared by wet chemical method.

TABLE II

Band gap energy estimated from UV visible absorption studies of pure and $\mathrm{Bi}, \mathrm{Zn}$ co-doped $\mathrm{Y}_{2} \mathrm{O}_{3}$ samples.

\begin{tabular}{c|c}
\hline \hline $\begin{array}{c}\text { Sample } \\
\text { name }\end{array}$ & Band gap energy $[\mathrm{eV}]$ \\
\hline B Pure & 5.28 \\
BBZ1 & 4.59 \\
BBZ2 & 4.59 \\
BBZ3 & 4.11 \\
C Pure & 5.3 \\
CBZ1 & 4.19 \\
CBZ2 & 4.59 \\
CBZ3 & 3.85
\end{tabular}

It has been observed from Table II of band gap energy estimated from UV visible absorption studies of pure and co-doped $\mathrm{Y}_{2} \mathrm{O}_{3}$ samples that band gap energy decreases with doping due to the disorder introduced in the system by two different dopants of different ionic radii with respect to $\mathrm{Y}$ and of different valency. From the estimated band gap energy it has been observed that the band gap energy shows red shift with doping. It is due to the formation of impurity band and trapping of dopant atoms, which leads to the generation of the defect states within the forbidden band [23]. Impurity band formation is an obvious consequence of increased doping concentration [24] and the trapping of the dopant atoms at the grain boundary leads to the introduction of the defect states within the forbidden band. With increasing dopant concentration, density of this dopant induced defect states increases, leading to the observed decrease of band gap or red shift. Actually, trapping of impurities and the introduction of defect states within the forbidden band gap region is intimately related to the disorder introduced in the system by doping. It is quite evident that more disorder should be introduced in the system with increasing dopant concentration as ionic radius of $\mathrm{Bi}$ is slightly greater than $\mathrm{Y}$ and ionic radius of $\mathrm{Zn}$ is less than $Y$. Hence band gap energy decreases with dopant concentration as already discussed in our previous paper [25].

\subsection{Photoluminescence}

In PL spectroscopy, photons with energy greater than the band gap of the material studied are directed onto the surface of the material, the incident monochromatic photon beam is partially reflected, absorbed, and transmitted by the material being probed. The absorbed photons create electron-hole pairs in the material. The electrons are excited to the conduction band, or to the energy states within the gap. In addition, electrons can lose part of their energy and transfer from the conduction band to energy levels within the gap. Photons produced as a result of the various recombinations of electrons and holes are emitted from the sample surface and it is the resulting photon emission spectrum that is studied in PL. The photon energies reflect the variety of energy states that are present in the material. Different energy states are produced by different defects, and by the many different ways impurities are incorporated into the lattice. As a consequence, a PL emission spectrum provides information concerning the point defect nature of a material by determining not only the presence, but also the type, of vacancies, interstitials, and impurities in the lattice. The improved luminescence efficiency from the phosphor can be achieved via energy transfer between the sensitizer (donor) and the acceptor [26].

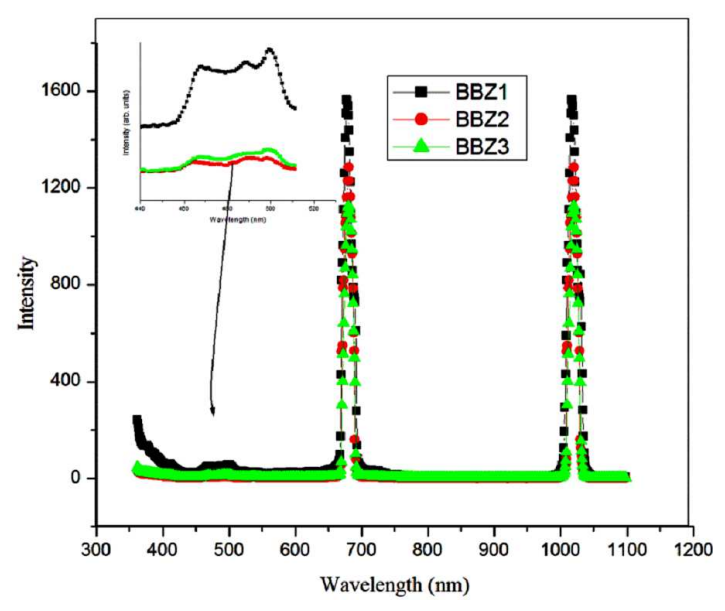

Fig. 8. PL emission of $\mathrm{Bi}, \mathrm{Zn}$ co-doped $\mathrm{Y}_{2} \mathrm{O}_{3}$ samples prepared by solvothermal method.

PL spectrum of pure and $\mathrm{Bi}, \mathrm{Zn}$ co-doped $\mathrm{Y}_{2} \mathrm{O}_{3}$ samples prepared by solvothermal and wet chemical method at excitation wavelength of $340 \mathrm{~nm}$ is shown in Figs. 8 and 9, respectively. PL emission of pure and co-doped $\mathrm{Y}_{2} \mathrm{O}_{3}$ sample prepared by solvothermal method shows three characteristic PL emission peaks around 500, 680, and $1020 \mathrm{~nm}$, Fig. 8. The PL peak around $500 \mathrm{~nm}$ corresponds to the radiative transition of an electron from the shallow donor level of interstitial zinc ions $\left(\mathrm{Zn}_{i}\right)$ to an acceptor level of neutral zinc vacancy, $\mathrm{V}_{\mathrm{Zn}}$ [27]. PL peak at $680 \mathrm{~nm}$ is commonly observed in Bi doped glasses under green excitation [28]. The original peak is at $700 \mathrm{~nm}$, hence the shift in peak to lower wavelength side may be due to the $\mathrm{Zn}$ dopant of different ionic size. The emission 


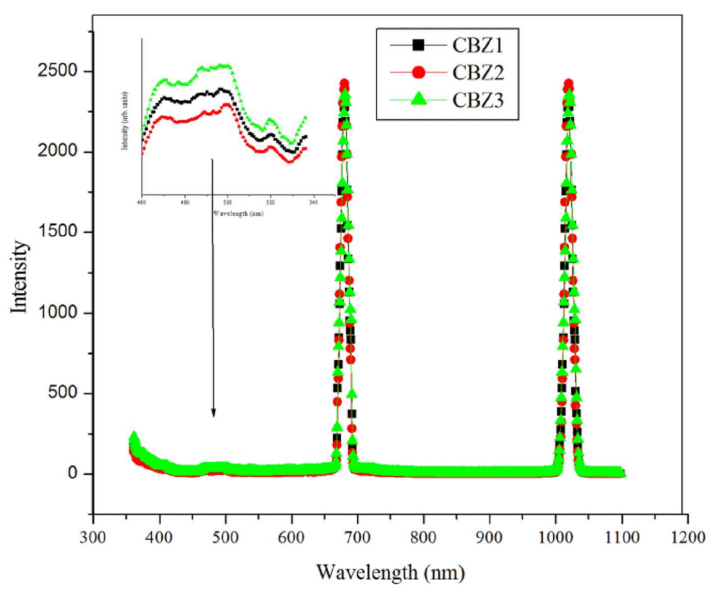

Fig. 9. As in Fig. 8 but for wet chemical method.

center in near infrared (NIR) region around $1020 \mathrm{~nm}$ is not clearly understood still now. Some researchers have reported the NIR emission due to $\mathrm{Bi}^{+}$and some are reported as $\mathrm{Bi}^{5+}$. The metallic bismuth $\left(\mathrm{Bi}^{0}\right)$ NPs also causes NIR emission and has been demonstrated by various researchers [25].

Presence of one PL emission peak for $\mathrm{Zn}$ and two peaks for $\mathrm{Bi}$ shows the dominance of $\mathrm{Bi}$ in the sample which is justified by the EDAX results, too. The PL spectrum shows emission in blue region $(500 \mathrm{~nm})$ due to $\mathrm{Zn}$ dopant and red and NIR region (680 $\mathrm{nm}$ and $1020 \mathrm{~nm}$ ) due to Bi dopant. Initial decrease and then increase of PL emission intensity may be attributed due to the presence of different dopants of different ionic size. PL emission intensity is found to be high for samples prepared by wet chemical method, when compared with solvothermal method. This may be due to the different preparation technique adopted. Also with increase in dopant concentration, PL emission intensity decreases for samples prepared by solvothermal method which may be due to concentration quenching, which is a threat for phosphors. But PL emission intensity increases for samples prepared by wet chemical method with increase in dopant concentration, which shows that till $1 \mathrm{wt} \%$ the samples have not undergone concentration quenching, which proves that these samples can be used as an efficient phosphor.

\section{Conclusion}

In this paper, structural, morphological, elemental and optical properties of pure and $\mathrm{Bi}, \mathrm{Zn}$ co-doped $\mathrm{Y}_{2} \mathrm{O}_{3}$ samples prepared by solvothermal and wet chemical method are analysed. XRD analysis shows that co-doped samples prepared by solvothermal method mostly show peaks due to $\mathrm{Y}_{2} \mathrm{O}_{3}$ whereas the co-doped samples with $0.5 \mathrm{wt} \%$ of daopant concentration show peaks which may be due to the presence of mixed phases of $\mathrm{ZnO}$ and $\beta-\mathrm{Bi}_{2} \mathrm{O}_{3}$ similar to the one with $0.25 \mathrm{wt} \%$ of dopant concentration prepared by wet chemical method. Other co-doped samples prepared by wet chemical method results in amorphous nature. SEM studies of the prepared samples show that homogeneous structures are present to some extent. EDAX studies show that Bi concentration of is more than that of Zn. UV-vis absorption studies of pure samples show the presence of the characteristic UV absorption band of $\mathrm{Y}_{2} \mathrm{O}_{3}$ at $250 \mathrm{~nm}$ that shifted to a higher region with increasing doping percent. When excited at $340 \mathrm{~nm}$ the samples prepared by solvothermal and wet chemical method shows PL emission around 500, 680, and $1020 \mathrm{~nm}$ in which PL peak around $500 \mathrm{~nm}$ corresponds to the radiative transition of an electron from the shallow donor level of $\mathrm{Zn}_{i}$ to an acceptor level of neutral $\mathrm{V}_{\mathrm{Zn}}$ of $\mathrm{Zn}$ while the peaks at 680 and $1020 \mathrm{~nm}$ corresponds to Bi. Since concentration quenching is not occurring for the samples prepared by wet chemical method, it has been suggested that wet chemical method is better method to prepare $\mathrm{Bi}$ and $\mathrm{Zn}$ co-doped samples for phosphor applications.

\section{References}

[1] M.E. Globus, B.V. Grinev, Inorganic Scintillators. New and Traditional Materials, Akta, Kharkov 2001 (in Russian).

[2] O.M. Bordun, V.V. Dmitruk, J. Appl. Spectrosc. 75, 208 (2008).

[3] A. Novoselov, A. Yoshikawa, M. Nikl, N. Solovieva, T. Fukuda, Cryst. Res. Technol. 40, 419 (2005).

[4] A.V. van de Gaats, G. Blasse, Chem. Phys. Lett. 243, 559 (1995).

[5] S. Qiang, C. Barthou, J.P. Denis, F. Pelle, B. Blanzat, J. Lumin. 28, 1 (1983).

[6] I.A. Meriloo, R.V. Melenina, Tr. IFA AN ESSR 39, 250 (1972).

[7] G. Bhavani, S. Ganesan, Int. J. Phys. 1, 32 (2012).

[8] A. Hristea, E.J. Popovici, L. Muresan, R. Grecu, E. Indrea, M. Vasilescu, in: Romopto 2003: Seventh Conf. on Optics, International Society for Optics and Photonics, 2004, p. 781.

[9] L. Muresan, E.J. Popovici, A. Hriste, E. Indrea, M. Vasilescu, in Ref. [8], p. 775 .

[10] E.J. Popovici, L. Muresan, H. Amalia, E. Indrea, M. Vasilescu, J. Alloys Comp. 434-435, 809 (2007).

[11] L. Muresan, E.J. Popovici, R. Grecu, L.B. Tudoran, J. Alloys Comp. 471, 421 (2009).

[12] C. García, L. Diaz-Torres, P. Salas, M. Guzman, C. Angeles-Chavez, Mater. Sci. Semicond. Process. 37, (2015).

[13] M. Pal, U. Pal, J.M.G.Y. Jiménez, F. PérezRodríguez, Nanoscale Res. Lett. 7, 11 (2012).

[14] X. Hao, E. Cho, C. Flynn, Y. Shen, S. Park, G. Conibeer, M. Green, Solar En. Mater. Solar Cells 93, 273 (2009).

[15] V. Fruth, A. Ianculescu, G. Voicu, J. Eur. Ceram. Soc. 26, 14 (2006).

[16] X. Peng, L. Manna, W. Yang, J. Wickham, E. Scher, A. Kadavanich, A.P. Alivisatos, Nature 404, 59 (2000).

[17] I. Pal, A. Agarwal, S. Sanghi, M. Aggarwal, Indian J. Pure Appl. Phys. 51, 18 (2013).

[18] S. Zhang, R. Xiao, J. Appl. Phys. 83, 3842 (1998). 
[19] R. Viswanath, H.S.B. Naik, Y.K.G. Somalanaik, P.K.P. Neelanjeneallu, K.N. Harish, M.C. Prabhakara, J. Nanotechnol. 2014, 1 (2014).

[20] L.L. Beecroft, C.K. Ober, Chem. Mater. 9, 1302 (1997).

[21] S. Kumar, N. Verma, M. Singla, Chalcogen. Lett. 8, 561 (2011).

[22] J. Dharma, A. Pisal, C. Shelton, Application Note Shelton, CT, Perkin-Elmer, 2009.

[23] R. Karmakar, S. Neogi, A. Banerjee, S. Bandyopadhyay, Appl. Surf. Sci. 263, 671 (2012).
[24] J.I. Pankove, J. Electrochem. Soc. 119, 156C (1972).

[25] G. Bhavani, S. Ganesan, Indian J. Pure Appl. Phys. 54, 307 (2016).

[26] P.T. Landsberg, Recombination in Semiconductors, Cambridge University Press, Cambridge 1991.

[27] T. Tatsumi, M. Fujita, N. Kawamoto, M. Sasajima, Y. Horikoshi, Jpn. J. Appl. Phys. 43, 2602 (2004).

[28] B. Denker, B. Galagan, V. Osiko, I. Shulman, S. Sverchkov, E. Dianov, Appl. Phys. B 98, 455 (2010). 